\title{
Hubungan Inteligensi Dengan Fungsi Eksekutif Pada Anak Gifted
}

\section{Relationship Between Intelligence And Executive Function To Gifted Children}

\author{
Aurelia Tyas Reneng Ayomi'1, Endang Widyorini², Maria Yang Roswita ${ }^{3}$ \\ 1, 2,3Fakultas Psikologi, Universitas Katolik Soegijapranata, Semarang \\ 1919e30066@student.unika.ac.id, 2widyorini@unika.ac.id, 3ita@unika.ac.id
}

\begin{abstract}
The purpose of this study was to determine the relationship between intelligence and executive function in gifted children. The research method used is correlational quantitative method with Spearman as a data analysis technique. Research participants are top class students who attend a private school in the city of Semarang, have an IQ above 130, and are 13-15 years old. Data collection on intelligence variables is by using the Culture Fair Intelligence Test (CFIT) and executive function using a neuropsychological test tool. The result of the study is that in general, intelligence is not significantly related to executive function in gifted children. Intelligence is related to two domains of executive function, namely inhibition and working memory but is not related to cognitive flexibility.
\end{abstract}

Keywords: executive function, gifted, intelligence.

Abstrak. Tujuan penelitian ini adalah untuk mengetahui hubungan antara inteligensi dengan fungsi eksekutif pada anak gifted. Metode penelitian yang digunakan adalah metode kuantitatif korelasional dengan Spearman sebagai teknik analisa data. Partisipan penelitian merupakan siswa kelas unggulan yang bersekolah di salah satu sekolah swasta di kota Semarang, mempunyai IQ di atas 130, dan berusia 13-15 tahun. Pengumpulan data variabel inteligensi adalah dengan Culture Fair Intelligence Test (CFIT) dan fungsi eksekutif menggunakan alat tes neuropsikologi. Hasil penelitian adalah secara umum, inteligensi tidak berhubungan signifikan dengan fungsi eksekutif pada anak gifted. Inteligensi berhubungan dengan dua domain fungsi eksekutif, yaitu inhibisi dan memori kerja namun tidak berhubungan dengan fleksibilitas kognitif.

Kata kunci : fungsi eksekutif, gifted, inteligensi.

\section{Pendahuluan}

Salah satu inovasi terbaru dalam dunia psikologi adalah diterapkannya ilmu neuropsikologi. Pada beberapa dekade terakhir, ilmu neuropsikologi berkembang cukup pesat. Di dalam ilmu neuropsikologi, ilmuwan mempelajari tentang fungsi eksekutif, yang selanjutnya akan disebut dengan FE. FE merupakan bagian dari fungsi kognitif. Anderson dalam Goldstein \& Naglieri (2014) mengatakan bahwa proses yang terkait dengan fungsi kognitif relatif banyak, tetapi unsur utamanya meliputi antisipasi, pemilihan tujuan, perencanaan, inisiasi aktivitas, pengaturan diri, fleksibilitas mental, penyebaran perhatian, dan pemanfaatan umpan balik.

Kajian mengenai fungsi eksekutif (FE) belum terlampau banyak. Goldstein, Naglieri, Princiotta, \& Otero dalam Goldtsein \& Naglieri (2014) mengungkapkan bahwa FE paling baik 
dipahami sebagai istilah umum yang digunakan untuk keragaman proses kognitif yang di area prefrontal korteks (cortex prefrontal/PFC) pada lobus frontal; proses tersebut termasuk perencanaan (planning), pemecahan masalah (problem solving), memori kerja (working memory), perhatian (attention), inhibisi (inhibitory), pemantauan diri (self monitoring), regulasi diri (self regulation), dan inisiasi (initiation). FE paling erat terkait dengan jaringan syaraf yang melibatkan PFC dan dipakai ketika individu dalam kondisi sadar, tujuan yang diarahkan pada pemikiran dan tindakan di bawah keadaan yang tidak familiar untuk secara langsung menghambat respon untuk suatu keinginan (Carlson, Zelazo, Faja, 2013). Baron dalam Goldstein \& Naglieri (2014) menyebutkan keterampilan terkait FE adalah dengan cara membiarkan seseorang untuk merasakan rangsangan dari lingkungannya, merespon secara adaptif, fleksibel dalam mengubah arah, mengantisipasi tujuan, mempertimbangkan konsekuensi, dan mengintegrasikan respon dengan akal sehat. Sedangkan Lezak dalam Goldstein \& Naglieri (2014) berpendapat bahwa FE mengacu pada kumpulan keterampilan kognitif dan perilaku yang saling terkait dan bertanggung jawab untuk mencapai tujuan, aktivitas yang diarahkan pada tujuan, dan termasuk kinerja tingkat tertinggi dari fungsi kognitif manusia seperti halnya kecerdasan, pemikiran, pengendalian diri, dan interaksi sosial. Definisi lain disebutkan oleh McCloskey, Perkin, Van Divner (2009) yang berpendapat FE sebagai suatu kelompok kognitif yang sangat spesifik yang dikumpulkan bersama untuk mengarahkan aktivitas kognisi, emosi, dan motorik, termasuk fungsi mental yang terkait dengan kemampuan untuk terlibat dalam membuat tujuan, mengorganisir, bertindak strategis, pengelolaan diri, perilaku yang diarahkan pada tujuan. Sedangkan Diamond (2013) menyebutkan FE merujuk pada suatu proses mental yang diperlukan ketika seseorang harus berkonsentrasi, memperhatikan, mengerjakan sesuatu secara otomatis atau mengandalkan naluri atau intuisi tidak disarankan, tidak cukup waktu, atau tidak mungkin dilakukan.

Diamond (2013) menggambarkan tiga FE "inti" yang memberikan dasar bagi keterampilan eksekutif yang lebih kompleks untuk dikembangkan. Ketiga FE "inti" ini adalah inhibitory, working memory, dan cognitive flexibility. Sejalan dengan Diamond, Carlson, Zelazo, \& Faja (2013) mengadopsi pendekatan "kesatuan dan keragaman" dari Miyake, dan menganggap FE sebagai kelas proses kognitif (Working Memory, Inhibition, Cognitive Flexibility) yang merupakan sebuah koordinasi yang menyeluruh dari proses-proses dalam mencapai suatu tujuan tertentu.

Domain FE yang pertama adalah fleksibilitas kognitif (cognitive flexibility/CF). Fleksibilitas kognitif (CF) seringkali disebutkan dengan nama lain shifting. Fleksibilitas kognitif seringkali disebut fleksibilitas mental, pergeseran mental dan terkait erat dengan kreativitas (Diamond, 2013; McCloskey, Perkins, \& Van Divner, 2009). Fleksibilitas kognitif didefinisikan sebagai kemampuan untuk menyesuaikan perilaku terhadap tuntutan perubahan lingkungan. Oleh karena itu, kemampuan ini penting untuk beradaptasi, pemecahan masalah secara kreatif, dan pemikiran "out-of-the-box". Tanpa CF, seseorang terjebak dalam pola perilaku yang kaku dan 
akan mengalami kesulitan beradaptasi dengan situasi baru. CF penting karena sifatnya yang adaptif, maka dapat dikatakan sebagai salah satu domain terpenting dari FE. Domain ini juga menunjukkan perubahan paling mendalam pada perkembangan anak dan remaja (Huizinga, Dolan, \& Van der Molen, 2006).

Domain FE selanjutnya adalah inhibisi (inhibitory control/IC). IC adalah kemampuan untuk menghambat perhatian pada distraktor (pengganggu) sehingga memungkinkan terjadinya perhatian selektif dan berkelanjutan. Kemampuan untuk menghambat kecenderungan perilaku yang kuat dapat membantu membuat seseorang menjadi fleksibel terhadap perubahan yang mungkin terjadi, serta menaati kesopanan sosial (Diamond, 2013). Istilah "inhibitory control" menunjukkan kemampuan untuk menahan respons yang tidak tepat atau prematur (baik motorik maupun kognitif), dan oleh karena itu defisit dalam IC kemungkinan terkait dengan perilaku impulsif pada level yang tinggi. IC mengacu pada kemampuan yang berhubungan dengan kognitif untuk menghambat respons dominan yang kuat namun tidak tepat dan mendukung respon yang tepat walaupun memiliki level yang lebih rendah. Kemampuan ini melibatkan kemampuan pemilihan strategi dengan hati-hati, mempertimbangkan perilaku alternatif, memperhatikan pengalihan tugas dan peralihan mental yang kompleks. Keterampilan ini sangat penting untuk mencegah atau memodifikasi tanggapan/respon (Bardo, Fishbein, \& Milich, 2011). Individu yang secara ekstrim memiliki IC yang rendah sering digambarkan sebagai Individu yang impulsif, egois, tidak rasional dan memiliki ketidakmampuan untuk menunda kepuasan (Goldstein \& Naglieri, 2014).

Domain FE yang terakhir adalah memori kerja (working memory/WM). WM atau dengan nama lain updating didefinisikan sebagai kemampuan untuk memantau dan memasukkan informasi juga untuk memperbarui konten memori dengan mengganti item lama dengan informasi yang lebih baru dan lebih relevan (Toll, Van der Ven, Kroesbergen, \& Van Luit, 2011). WM adalah proses kognitif yang fungsi utamanya adalah untuk memfasilitasi dan meningkatkan kapasitas fungsi pengkodean, penyimpanan, dan pengambilan yang penting untuk pembelajaran dan pemrosesan informasi tingkat tinggi (Dehn, 2011). WM merupakan salah satu proses kognitif utama yang mendasari pemikiran dan pembelajaran. WM diperlukan karena memungkinkan terjadinya representasi informasi secara internal untuk memandu pengambilan keputusan dan perilaku terbuka.

Kemampuan kognitif dan kegiatan terkait otak terletak di bagian depan dari lobus frontal, yang disebut dengan prefrontal korteks (cortex prefrontal/PFC). PFC sering kali disebut sebagai area kontrol eksekutif yang letaknya tertanam dalam jalur syaraf sehingga dapat mengkoordinasikan dan mengintegrasikan fungsi semua data (Sousa, 2009). Studi pada bidang neuropsikologi menunjukkan pertumbuhan dan perubahan yang signifikan pada beberapa 
daerah PFC sepanjang masa remaja, yang berperan dalam mengontrol impuls dan perencanaan, serta sistem limbik, yang terkait dengan pemrosesan informasi.

Di sepanjang rentang usia, masa remaja adalah periode kritis untuk pematangan proses neurobiologis yang mendasari fungsi kognitif yang lebih tinggi serta perilaku sosial dan emosional (Yurgelun \& Todd, 2007). Pada remaja, otak masih berkembang dan masih bekerja dalam proses. Perubahan dramatis pada struktur otak mencakup emosi, penilaian, perilaku organisasi, dan kontrol diri yang berganti antara masa pubertas dan masa dewasa awal. Dalam sebuah studi, proses informasi remaja mengenai emosi berbeda daripada orang dewasa. Masa remaja awal (11-13 tahun) cenderung menggunakan amigdala, sebuah bentuk almond yang kecil yang terdapat di dalam lobus temporal yang melibatkan reaksi emosi dan insting. Masa remaja yang lebih tua (14-17tahun) menunjukkan pola-pola yang menyerupai masa dewasa, menggunakan lobus frontalis yang menguasai perencanaan, penalaran, penilaian, regulasi emosi, dan kontrol impuls dan selanjutnya mengembangkan penilaian yang lebih akurat dan masuk akal (Papalia, Feldman, \& Martorell, 2014). Perubahan yang lain terutama berkenaan dengan proses myelinisasi dan pemangkasan sinaptik (Wade \& Carol, 2007). Di dalam otak, di area yang bernama frontal-parietal, yang di dalamnya termasuk jaringan area abu dan putih tampaknya menjadi daerah utama kecerdasan. Inteligensi berkaitan dengan efisiensi yang terjadi di otak. Area inteligensi menyebar di seluruh bagian otak, tidak dipusatkan di satu area saja (Haier dalam Kerr, 2009). Godoy mendefinisikan inteligensi sebagai kemampuan untuk belajar dari suatu pengalaman dan beradaptasi dengan lingkungannya (Godoy, Dias, \& Seabra, 2014). Sedangkan Wechsler (Ardila, 2018; Kent, 2017) mendefinisikan inteligensi sebagai kapasitas individu untuk bertindak dengan tujuan, untuk berpikir secara rasional, dan untuk menangani lingkungan secara efektif.

Salah satu anak yang unik adalah anak dengan cerdas istimewa, atau lebih sering disebut dengan gifted. Renzulli (2005) menyebutkan seorang anak gifted mempunyai inteligensi di atas rata-rata sebagai syarat utama, kreativitas yang tinggi, serta motivasi dan komitmen yang tinggi juga terhadap tugas-tugas. Inteligensi yang sangat tinggi tersebut memungkinkan anak gifted mampu secara cepat beradaptasi dengan tugas dan lingkungannya. Friedman, Miyake, Corley, Young, DeFries, Hewwit (2006) menyebutkan anak gifted memiliki kemampuan yang melebihi kemampuan anak lain pada umumnya dan menunjukkan hasil kerja yang sangat tinggi. Anak gifted berbeda dalam banyak aspek (kognitif, afektif, sosial) dibandingkan dengan anak-anak normal. Kecerdasan yang dimiliki anak gifted merupakan kecerdasan bawaan, yang sering disebut dengan fluid intelligence (Kent, 2017). Fluid intelligence adalah kemampuan untuk bernalar yang biasanya diukur dengan menggunakan tugas-tugas yang membutuhkan pemecahan masalah baru (Cattel \& Horn dalam Apsvalka, Gross, Ramsey, 2019). Inteligensi yang sangat tinggi mempunyai potensi untuk fungsi kognitif yang tinggi yang dihasilkan dari interaksi 
faktor yang kompleks, termasuk dari genetik dan lingkungan (Saenz, Riba, Martinez, \& Botella, 2020).

Menurut ahli neuropsikologi, pada perkembangannya, fungsi kognitif terutama FE berhubungan dengan inteligensi. Ciri anak dengan inteligensi yang sangat tinggi adalah anak mempunyai penalaran yang baik, dapat memecahkan masalah dengan baik, mampu menggeneralisasi suatu masalah yang rumit menjadi suatu hal yang sederhana dan mudah dipahami, menunjukkan daya imajinasi yang luar biasa, memiliki perbendaharaan kosa kata yang sangat kaya dan mampu mengartikulasikannya dengan baik, memiliki daya ingat jangka panjang (long term memory) yang kuat, serta mampu memikirkan beragam gagasan atau persoalan dalam waktu yang bersamaan dan cepat mengaitkan hubungan satu hal dengan hal yang lain (Ferreira, Zanini, \& Seabra, 2015). Chichekian \& Shore (2017) mengatakan dengan potensi yang sangat besar tersebut, anak gifted mempunyai fleksibilitas kognitif (CF) yang baik (mampu mengkategorikan masalah menjadi bermakna dan mampu membuat solusi yang relevan), metakognisi (terkait dengan FE dan regulasi diri), strategic planning (jeda lama pada tahap awal penyelesaian masalah), mendahulukan kompleksitas dan penyelesaian masalah, mempunyai daya ingat yang sangat baik (mengembangkan memori kerja (WM) untuk mengatasi masalah), serta mempunyai pengetahuan yang luas mengenai berbagai hal. Penelitian-penelitian yang telah dilakukan sebelumnya menyebutkan bahwa ada keterkaitan FE dengan inteligensi. Seperti penelitian yang dilakukan oleh Arffa (2007) menyebutkan bahwa IQ dengan skala penuh berhubungan signifikan dengan FE. Anak yang mempunyai inteligensi tinggi (IQ di atas 130) seharusnya mempunyai korelasi positif dengan FE, atau dapat dikatakan mempunyai FE yang baik. Seperti pada penelitian yang dilakukan oleh Ardila, Pineda, Roselli (2000), Baron \& Byrne (2003) dan Mahone, Hagelthorn, Cutting, Schuerholz, Pelletier, Rawlins, Singer, \& Denckla (2002) menemukan bahwa FE berhubungan dengan inteligensi, terutama ketika sampel berisi seseorang dengan IQ tinggi dan terdapat varian yang memadai. Ardilla, Pineda, Roselli (2000) melakukan penelitian dengan partisipan remaja. Hasilnya adalah tes verbal fluency berkorelasi dengan Verbal Intelligence Quotient (IQ) dan full scale IQ.

Namun pada kenyataannya, meskipun siswa gifted mempunyai inteligensi yang sangat tinggi namun ada juga kelemahan yang dimiliki, salah satunya adalah FE. Beberapa anak gifted ditemukan mempunyai FE yang kurang baik. Kurangnya kemampuan FE pada siswa gifted menjadikan berbagai masalah yang akan berdampak terhadap diri sendiri maupun orang lain. Silverman (2013) dan Pfieffer (2018) menyebutkan masalah yang dihadapi siswa gifted terkait dengan FE yaitu masalah perencanaan dan pengorganisasian yang mengganggu kinerja sekolah, kurangnya manajemen waktu, pekerjaan sering kali dikerjakan di saat-saat terakhir, kurang dapat mengurutkan ekspresi lisan dan tertulis, ketidakmampuan mengungkapkan bagaimana cara mendapatkan jawaban, impulsif, serta membuat keputusan tanpa disertai dengan pemikiran 
yang matang. Diketahui bahwa kemampuan pemecahan masalah serta perencanaan dan pengaturan waktu dalam pengerjaan tugas untuk mendapatkan hasil yang baik membutuhkan fleksibilitas kognitif (Cognitive Flexibility/CF) yang baik. Demikian juga untuk kemampuan mengontrol diri dan mengontrol emosi yang berhubungan dengan inhibitori (Inhibitory Control/IC), serta kemampuan analisa, berpikir, bernalar, dan belajar membutuhkan kemampuan memori kerja (Working Memory/WM).

Berdasarkan uraian di atas dapat diketahui bahwa inteligensi yang dimiliki anak gifted berhubungan dengan FE. Namun belum banyak bukti yang ditemukan disebabkan kurangnya penelitian yang meneliti hubungan tersebut. Oleh sebab itu, peneliti ingin menguji hipotesis apakah terdapat hubungan antara inteligensi dan fungsi eksekutif (FE) pada anak gifted.

\section{Metode}

Penelitian ini menggunakan pendekatan kuantitatif dengan strategi penelitian korelasional (Sugiyono, 2017). Variabel penelitian meliputi fungsi eksekutif (FE) sebagai variabel tergantung dan inteligensi sebagai variabel bebas.

Partisipan penelitian dalam penelitian ini merupakan siswa kelas unggulan yang ada di salah satu sekolah swasta di kota Semarang, mempunyai IQ di atas 130, berjumlah 63 orang, dengan siswa laki-laki berjumlah 34 orang dan siswa perempuan berjumlah 29 orang. Usia siswa yang diambil sebagai partisipan adalah rentang usia 13-15 tahun.

Metode pengumpulan data untuk variabel inteligensi menggunakan dokumentasi sekolah sedangkan untuk variabel FE menggunakan alat tes neuropsikologi. Alat ukur inteligensi yang digunakan untuk penyaringan anak gifted adalah Culture Fair Intelligence Test (CFIT). Alat tes tersebut digunakan karena validitas dan reliabilitasnya tinggi, mengukur kecerdasan bawaan, serta memberikan sebuah estimasi kecerdasan yang relatif bebas dari pengaruh budaya dan bahasa. Pengumpulan data FE dengan menggunakan alat tes neuropsikologi, yaitu Wisconsin Card Sorting Test (WCST) dan Stroop Color and Word Task versi online dari Psytoolkit.org, Trial Making Test (TMT), dan Digit Span. Pengumpulan data FE dilakukan di sekolah selama dua hari, dibantu oleh asisten-asisten penelitian yang terlatih.

Setelah terkumpul dengan lengkap, data kemudian dianalisis menggunakan komputer dengan program Statistical Packages for Social Sciences (SPSS) 21.

\section{Hasil}

Jumlah keseluruhan partisipan penelitian yang menjadi dasar analisis data berjumlah 63 orang siswa gifted. Data deskriptif partisipan penelitian dapat dilihat pada Tabel 1. 


\section{Tabel 1}

Data Deskriptif partisipan penelitian

\begin{tabular}{cccc}
\multicolumn{2}{c}{ Demografi siswa gifted } & Frekuensi & $\%$ \\
\hline Usia & 13 th & 12 & $19 \%$ \\
& 14 th & 43 & $68 \%$ \\
& 15 th & 8 & $13 \%$ \\
Jenis & Laki-laki & 34 & $54 \%$ \\
Kelamin & Perempuan & 29 & $46 \%$ \\
Nilai IQ & $130-135$ & 42 & $66 \%$ \\
& $136-140$ & 15 & $24 \%$ \\
& $141-145$ & 5 & $8 \%$ \\
\hline & $146-150$ & 1 & $2 \%$
\end{tabular}

Dari hasil uji normalitas dengan menggunakan kolmogorov smirnov diketahui bahwa data yang terkumpul tidak berdistribusi normal. Ketidaknormalan data dapat dipahami karena partisipan memiliki inteligensi yang jauh di atas rata-rata sehingga merupakan partisipan yang terseleksi dengan ketat. Oleh sebab itu, untuk pengujian hipotesis menggunakan uji nonparametrik korelasi Spearman.

Analisis data dengan teknik korelasi Spearman dapat diperoleh hasil seperti yang tercantum pada Tabel 2 di bawah ini.

Tabel 2

Hasil koefisien korelasi IQ dan alat tes neuropsikologi

Spearman's IQ

Rho

\begin{tabular}{llr}
\hline Backward & Correlation coefficient & $.347^{* *}$ \\
& Sig. (2-tailed) & .005 \\
& $\mathrm{~N}$ & 63 \\
Sequencing & Correlation coefficient & .066 \\
& Sig. (2-tailed) & .610 \\
& $\mathrm{~N}$ & 63 \\
Stroop & Correlation coefficient & $.298^{*}$ \\
& Sig. (2-tailed) & .018 \\
& $\mathrm{~N}$ & 63 \\
TMT & Correlation coefficient & -.105
\end{tabular}


Jurnal Ilmiah Psikologi Candrajiwa

Vol. 6, No. 2, Desember 2021, 134-150.

Spearman's

IQ

Rho

\begin{tabular}{llr}
\hline & Sig. (2-tailed) & .414 \\
\multirow{3}{*}{ WCST } & $\mathrm{N}$ & 63 \\
& Correlation coefficient & .104 \\
& Sig. (2-tailed) & .415 \\
\hline & $\mathrm{N}$ & 63
\end{tabular}

ISSN 2442-8051 (Print)

https://jurnal.uns.ac.id/candrajiwa

Hasil penelitian menunjukkan korelasi yang tidak signifikan antara inteligensi dengan fungsi eksekutif pada anak gifted $(\mathrm{r}=0,104 ; p<0,05)$. Dengan demikian, hipotesis ditolak. Namun demikian, penelitian ini juga dapat menunjukkan bahwa tidak semua domain FE dipengaruhi oleh inteligensi. Hasil pengukuran ketiga domain yang terdapat pada FE menunjukkan signifikansi yang berbeda-beda. Memori kerja (working memory/WM) yang diukur dengan alat tes Digit Span Sequencing tidak ditemukan hubungan yang signifikan $(\mathrm{r}=0,066 ; \mathrm{p}<0,05)$. Begitu pula dengan domain fleksibilitas kognitif (cognitive flexibility/CF) yang diukur dengan alat ukur Trail Making Test (TMT) tidak ditemukan hubungan yang signifikan $(r=-0,105 ; p<0,05)$. Meskipun demikian, terdapat hubungan yang signifikan untuk inteligensi dan memori kerja (working memory/WM) dari alat ukur Digit Span Backward ( $\mathrm{r}=0,347 ; p<0,05)$, dan inteligensi dengan kontrol inhibitori (inhibitory control/IC) dari alat ukur Stroop Color and Word Task $(\mathrm{r}=0,298 ; p<0,05)$.

\section{Pembahasan}

Inteligensi pada anak gifted didapatkan dari mereka lahir atau lebih tepatnya didapatkan sebagai faktor genetik, yang dinamakan fluid intelligence. Dalam hal ini fluid intelligence sering kali diasosiasikan dengan orang cerdas dan didefinisikan sebagai kemampuan untuk penalaran, pemecahan masalah, pemikiran abstrak, dan dapat mempelajari sesuatu dengan cepat. Selain terkait dengan faktor genetik, fluid intelligence juga terkait dengan fungsi neurologis (Kyllonen \& Kell, 2017). Sebuah penelitian yang dilakukan oleh Geake \& Dodson (2005) menemukan bahwa bagian otak yang bernama alpha power di bagian lobus frontal dan lobus oksipitalis pada remaja gifted beroperasi dengan kematangan yang setara dengan usia lima tahun di atasnya. Hal ini selaras dengan yang ditemukan oleh Kerr (2009) bahwa otak anak gifted memproses informasi di otak dengan lebih cepat dan efisien dari pada sebayanya yang tidak gifted.

Penelitian tentang inteligensi dan FE pada anak gifted belum banyak dilakukan. Beberapa penelitian yang ditemukan menyebutkan bahwa inteligensi berkaitan dengan FE. Penelitian yang dilakukan oleh Yazid, Zainun, Khan, dan Saleh (2018) membuktikan bahwa pada anak gifted, tugas-tugas yang melibatkan kognisi dan kecerdasan sangat dipengaruhi oleh FE. Penelitian tersebut memperlihatkan adanya hubungan yang signifikan antara kognisi, kecerdasan, dan FE. 
Keterampilan FE yang diajarkan di sekolah melalui pengelolaan buletin sekolah mampu meningkatkan FE yang dimiliki siswa gifted di sekolah. Demikian pula penelitian yang dilakukan oleh Ardila, Pineda, Roselli (2000), Baron \& Byrne (2003) menemukan bahwa FE berhubungan dengan inteligensi, terutama ketika sampel berisi seseorang dengan IQ tinggi dan terdapat varian yang memadai. Ardila, Pineda, Roselli (2000) melakukan penelitian dengan partisipan remaja. Hasilnya adalah tes verbal fluency berkorelasi dengan Verbal Intelligence Quotient (IQ) dan full scale IQ.

Penelitian ini mendapatkan hasil bahwa inteligensi berhubungan dengan inhibisi (inhibitory control/IC) dan memori kerja (working memory/WM). Pertama akan dibahas mengenai hubungan inteligensi dengan IC. PFC merupakan bagian otak yang berada tepat di belakang dahi. di bagian ini diketahui memiliki peran untuk membuat rencana dan mengambil keputusan. Di dalam PFC terdapat grey matter dan white matter. Grey matter (lapisan abu-abu) yaitu tempat badan sel berada dan merupakan tempat paling aktif di otak, terdiri dari badan sel syaraf, dan merupakan struktur yang menampung inti neuron. White matter (lapisan putih) terdiri dari akson bermyelin yang membentuk hubungan antar otak. Grey matter bisa menjadi tanda adanya kontrol diri. Grey matter juga berfungsi untuk pembelajaran tingkat tinggi, termasuk di dalamnya attention, memory, dan thought. Sedangkan white matter berfungsi agar sinyal di dalam akson bergerak lebih cepat yang penting untuk fungsi motorik dan sensorik. Pada anak gifted, bagian grey matter ditemukan mempunyai luasan ukuran yang lebih besar dan ukuran yang berbeda dari pada anak yang tidak gifted (Maclntyre, 2008; Miyake, Friedman, Emerson, Witzki, Howerter, Wager, 2000). Hal ini membuktikan hasil penelitian yang dilakukan. Pada anak gifted, grey matter yang lebih besar menjadikan anak lebih baik dalam melakukan perencanaan (planning), memberikan perhatian (attention), daya ingat (memory), dan daya pikir (thought) (Miyake, Friedman, Emerson, Witzki, Howerter, Wager, 2000). Otak yang dimiliki anak gifted mempunyai kontrol kognitif yang baik sehingga meskipun otak meminta aktivasi terus menerus dari otak bagian lain, anak gifted tetap dapat mengontrol diri untuk komitmen terhadap tugas-tugas (Geake \& Dodson, 2005; Dombrowski \& Mrazik, 2010) dan pengendalian diri akan meningkat sesuai usia (Maclntyre, 2008).

Hasil penelitian ini juga membuktikan bahwa inteligensi berhubungan dengan memori kerja (working memory/WM). Beberapa penelitian sebelumnya membahas hal tersebut. Pada pengukuran inteligensi dan FE, domain yang banyak berhubungan signifikan adalah WM (Ferreira, Zanini, \& Seabra, 2015; Saenz, Riba, Martinez, \& Bottella, 2020; Hornung, Brunner, Reuter, \& Martin, 2011; Friedman, Miyake, Corley, Young, De Fries, \& Hewwit, 2006; Fugate, Gentry, Zentall, 2013; Benedek, Jauk, Sommer, Arendasy, \& Neubauer, 2014; Al-Hmouz \& Abu Hamour, 2017), terutama pada anak-anak (Giofre, Mammarella, \& Cornoldi, 2013). Diantara ketiga domain, WM mempunyai kaitan signifikansi yang paling erat dengan inteligensi. Fugate, 
Gentry, \& Zentall (2013) melakukan penelitian yang menghasilkan inteligensi berhubungan signifikan dengan WM pada anak gifted, yang dihitung dengan backward digit span. Anak gifted mempunyai working memory yang lebih baik daripada anak normal yang tidak gifted (Leikin, Paz-Baruch \& Leikin, 2013; van Viersen, Kroesbergen, Slot, \& de Bree, 2014). WM mengacu pada pemantauan informasi yang masuk serta mengganti informasi usang dengan informasi baru yang relevan untuk tugas saat ini (Benedek, Jauk, Sommer, Arendasy, Neubauer, 2014). WM terdiri dari proses yang bekerja dengan materi dari Long Term Memory (LTM) dan Short Term Memory (STM). WM bukan tentang penyimpanan informasi sementara atau jangka panjang; itu adalah fungsi LTM dan STM. Namun, WM adalah proses kognitif yang fungsi utamanya adalah untuk memfasilitasi dan meningkatkan kapasitas fungsi pengkodean, penyimpanan, dan pengambilan yang penting untuk pembelajaran dan pemrosesan informasi tingkat tinggi (Dehn, 2011). Pada anak gifted, mekanisme kontrol diri terkait WM juga terkait dengan IC yang baik. Anak gifted dapat menghambat informasi-informasi yang tidak relevan dan mengalihkan pemrosesan informasi agar informasi baru yang seharusnya diingat dapat diterima dengan baik. Pada anak gifted, corpus collosum lebih besar dari pada anak normal sehingga terdapat lebih banyak ruang di otak untuk menyalurkan informasi dari satu bagian otak ke bagian otak yang lain dan pada akhirnya kedua bagian otak dapat tersinkronisasi dengan baik (Maclntyre, 2008). WM menjadi kapasitas yang mendasari proses kognitif kompleks dan kemampuan tersebut dimiliki oleh anak gifted (Dehn, 2011). Namun, mekanisme yang tepat dibalik kapasitas WM yang baik tersebut belum diketahui.

Meskipun inteligensi berhubungan signifikan dengan domain inhibisi (IC) dan memori kerja (WM), namun tidak demikian dengan domain fleksibilitas kognitif (CF). Beberapa penelitian sebelumnya ditemukan bahwa inteligensi berhubungan lemah atau bahkan tidak berhubungan dengan fleksibilitas kognitif (Benedek, Jauk, Sommer, Arendasy, \& Neubauer, 2014; Friedman, Miyake, Corley, Young, DeFries, \& Hewitt, 2006; Davis, Pierson, \& Finch, 2011). Aspek pertama CF adalah dapat melihat sesuatu hal dari berbagai sudut pandang. Kedua meliputi kemampuan untuk mengubah cara berpikir (Diamond, 2013). Pada anak usia dini, perkembangan dorsolateral prefrontal cortex dipengaruhi oleh stimulasi dari lingkungannya (Wendelken, Bunge, \& Carter, 2008). Anak usia dini merespon sesuatu dari aturan yang telah dipelajari sebelumnya (Georgopoulos dalam Diamond, 2013) dan pengalamannya (Maclntyre, 2008). Namun pada anak yang lebih besar tidak demikian. Mereka dapat beralih dari satu hal ke hal yang lain secara fleksibel berdasarkan paradigma dari sebuah pengalaman dan uji coba (Gupta dalam Diamond, 2013). CF bertolak belakang dengan kekakuan. Pada anak gifted, CF seringkali sulit untuk dilakukan karena mereka mempunyai cara berpikir yang berbeda, karakter sosial emosional yang berbeda, serta lintasan dan jalur perkembangan yang berbeda dari anak yang tidak gifted (Maclntyre, 2008). Karakteristik tersebut salah satunya adalah perfeksionisme yang menjadi ciri 
khas anak gifted. Perfeksionisme yang dimiliki seringkali menjadikan anak gifted kaku dan tidak mudah beralih dari satu hal ke hal yang lainnya (Guignard, Jacquet, dan Lubart, 2012).

Hasil yang tidak konsisten antara inteligensi dengan domain FE juga didapatkan hasil bahwa secara umum, inteligensi memang tidak selalu berhubungan dengan FE. Penelitian yang dilakukan juga tidak mendapatkan hasil yang konsisten. Data dan bukti bahwa tes inteligensi berhubungan dengan FE tidaklah kuat (Arffa, 2007; Godoy, Dias, Seabra, 2013). Beberapa penelitian dengan subjek dewasa menemukan bahwa FE tidak berhubungan dengan IQ (Arffa, 2007). Hasil penelitian ini juga membuktikan bahwa FE merupakan sebuah keterampilan, sehingga dapat dikatakan bahwa FE merupakan sesuatu yang dapat dipelajari dan dilatihkan. Menurut Miller (2007), FE dianggap terlibat dalam semua jenis kognisi tingkat tinggi . Namun FE sering kali tumpang tindih dengan apa yang dimaksud dengan kecerdasan berperilaku (Arffa, 2007).

Beberapa penelitian yang dilakukan mendapatkan hasil bahwa tidak semua domain dari FE dipengaruhi oleh inteligensi. Carlson, Zelazo, \& Faja (2013) menyebutkan bahwa FE tidak dipengaruhi oleh inteligensi, namun lebih banyak dipengaruhi oleh faktor sosial ekonomi, jenis kelamin budaya, bahasa, pengasuhan, interaksi gen-lingkungan, dan pola tidur.

Faktor yang memengaruhi FE yang pertama adalah faktor sosial ekonomi. Blair \& Razza (2007) menyebutkan bahwa tingkat sosial ekonomi yang rendah berkinerja relatif rendah di FE. Tingkat pendidikan orang tua juga berpengaruh terhadap FE dan perkembangan bahasa anak. Selain itu anak yang sering berpindah tempat tinggal, trauma, stres masa kecil juga dapat mempengaruhi FE. Briggs, Reis, Sullivan (2008) melakukan penelitian pada anak gifted dan menemukan bahwa secara budaya, bahasa, dan etnis yang berbeda serta siswa dari keluarga yang kurang mampu secara ekonomi kurang teridentifikasi sebagai anak gifted.

Faktor jenis kelamin juga memengaruhi FE. Perbedaan jenis kelamin memengaruhi kinerja pada beberapa pengukuran FE pada anak dan remaja. Satu kemungkinan, yaitu cool EF (abstrak dekontekstual, ketergantungan pada kemampuan verbal) lebih baik pada perempuan sedangkan hot EF (representasi fleksibel pada penguatan atau stimulus) lebih baik pada laki-laki. Hal ini konsisten dengan riset yang telah dilakukan sebelumnya yang didapatkan hasil bahwa fungsi orbitori frontal cortex (OFC) berkembang lebih cepat pada laki-laki dan di bawah kendali hormon, sedangkan bahasa diperoleh lebih cepat pada anak perempuan. Meskipun demikian, pada penelitian ini, jenis kelamin bukan merupakan faktor yang mempengaruhi korelasi antara inteligensi dan FE. Hal ini dapat terjadi karena pola pengasuhan yang sama antara anak laki-laki dan perempuan yang akan dijelaskan pada faktor tentang pengasuhan di bawah ini.

Faktor ketiga yang memengaruhi FE adalah budaya dan pengasuhan. Pola pengasuhan interaktif dari orang tua ke anak menumbuhkan perkembangan FE, terutama sensitivitas, kepercayaan diri, serta pola pikir anak. Sensitivitas berisi tentang respon yang dilakukan dengan 
konsisten dan tepat, menyediakan informasi yang mendukung harapan anak-anak serta dapat diprediksi. Pengasuhan yang mendukung anak untuk menyelesaikan masalah sesuai usia akan membuat anak lebih mudah memiliki FE yang baik. Cara orang tua memberikan respon dan memfasilitasi anak atas suatu masalah atau kejadian akan diikuti anak pada saat anak merespon dan mengontrol diri, yang hal tersebut merupakan pusat dari FE (Fay-Stammbach, Hawes, Meredith, 2014). Hal tersebut didukung dengan penelitian longitudinal yang dilakukan oleh Bernier, Carlson, Descheness, dan Matte-Gagne (2011) yang menemukan bahwa anak dengan kualitas pengasuhan dan memiliki kelekatan dengan ibu yang sangat baik akan mempunyai tingkat performansi FE baik di usia 3 tahun.

Bahasa menjadi faktor keempat yang memengaruhi FE. Penelitian membuktikan bahwa jumlah kosakata yang dimiliki berhubungan dan dapat digunakan untuk memprediksi perkembangan FE. Carlson, Zelazo, \& Faja (2013) mengemukakan bahwa aspek kunci dalam FE, yaitu kontrol inhibitori, berkembang lebih cepat pada anak-anak yang memiliki pengalaman luas terkait dengan bahasa. Dalam setiap kasus, contoh yang bermacam-macam menyebutkan bahwa anak yang terbiasa dengan dua bahasa lebih baik pada tes FE daripada yang hanya satu bahasa.

Faktor selanjutnya yang memengaruhi FE adalah interaksi antara gen dan lingkungan. Carlson, Zelazo, \& Faja (2013) menyimpulkan bahwa terdapat faktor umum yang diwariskan serta pengaruh genetik tambahan yang unik untuk domain FE tertentu (inhibitory control dominan, memperbarui working memory, dan shifting). Penelitian eksperimen yang dilakukan menunjukkan bahwa intervensi meningkatkan aspek kinerja FE pada anak-anak dan membuktikan bahwa FE adalah hal diwariskan, maka dapat dipastikan gen dan lingkungan mempunyai pengaruh untuk perkembangan FE. Hormon kortisol yang dimiliki orang tua akan diturunkan ke anak. Hormon kortisol dan tingkat stres yang tinggi pada orang tua juga dapat berpengaruh pada FE. Anak dengan orang tua berpendapatan tinggi akan mempunyai FE yang lebih baik dari pada anak dengan orang tua berpendapatan rendah (Lickliter, 2012). Pada anakanak, hormon kortisol berhubungan negatif dengan performansi FE, terutama yang mengukur working memory dan selective attention (Rhoades, Greenberg, Lanza \& Blair, 2011; Aubry, Beatrice, Gonthier, 2018).

Faktor yang memengaruhi FE yang terakhir adalah pola tidur. Carlson, Zelazo, \& Faja (2013) menyebutkan bahwa tidur bayi dapat memprediksi FE ketika balita, bahkan ketika SES, kemampuan kognitif, dan kemampuan eksekutif telah dikendalikan sebelumnya. Bayi berusia antara 12-18 bulan yang proporsi tidurnya lebih banyak terjadi pada malam hari memiliki FE yang lebih baik ketika menginjak 26 bulan dan sekali lagi pada 4 tahun, khususnya dalam domain kontrol impuls. Hubungan ini unik untuk FE, bukan kemampuan kognitif umum. Kemudian pada perkembangannya, pola tidur anak juga dapat memprediksi FE selama masa remaja. Anak-anak 
yang mempunyai pola tidur yang baik, akan cenderung mempunyai FE yang baik pula pada akhir masa remajanya.

Penelitian ini memiliki beberapa keterbatasan, yaitu jumlah anak gifted yang tidak terlampau banyak, hanya berjumlah 63 orang yang tentunya masih belum dapat menggambarkan keadaan yang sesungguhnya. Kemudian, peneliti menggunakan alat tes dengan komputer sehingga ada kemungkinan bahwa anak tidak terbiasa mengerjakan soal berbasis komputer sehingga ada kesulitan ketika mengerjakan. Demikian juga dengan bahasa. Bahasa yang digunakan ada beberapa yang menggunakan bahasa Inggris sehingga membuat anak kesulitan karena bukan menggunakan bahasa Indonesia seperti yang digunakan dalam keseharian. Keterbatasan penelitian yang terakhir adalah belum banyak penelitian yang meneliti inteligensi dengan fungsi eksekutif pada anak gifted sehingga penulis cukup kesulitan mendapatkan referensi dari hasil penelitian sebelumnya.

\section{Kesimpulan}

Berdasarkan hasil penelitian diperoleh hasil korelasi Spearman $r=0.104$ yang berarti tidak ada hubungan yang signifikan antara inteligensi dengan fungsi eksekutif pada anak gifted. Inteligensi berhubungan dengan dua domain fungsi eksekutif, yaitu inhibisi dan memori kerja namun tidak berhubungan dengan fleksibilitas kognitif.

\section{Implikasi}

Dilihat dari keterbatasan penelitian pada penelitian ini, maka untuk penelitian selanjutnya diharapkan menggunakan partisipan dengan jumlah yang lebih besar. Kemudian, diperlukan penelitian lanjutan terkait topik ini. Selain itu, peneliti selanjutnya dapat menemukan variabel lain yang dapat mengkorelasikan inteligensi dengan fungsi eksekutif, misalnya dengan menambah variabel moderator.

Bagi sekolah dan orang tua yang mempunyai anak gifted, dapat mengajarkan keterampilanketerampilan fungsi eksekutif, yaitu keterampilan yang dapat meningkatkan kemampuan berpikir. Misalnya anak diajarkan untuk merencanakan sesuatu, menyusun strategi, dan konsisten dalam pengerjaan. Serta membimbing pada saat anak mulai mendapat masalah ketika mengerjakan sesuatu hal tersebut sehingga pada akhirnya mendapat hasil akhir yang diinginkan. 


\section{Daftar Pustaka}

Arffa, S. (2007). The Relationship if Intelligence to Executive Function and Non-Executive Function Measures in a Sample of Average, Above Average, and Gifted Youth. Archives of Clinical Neuropsychology, 22(8),969-978. https://doi.org/10.1016/j.acn.2007.08.001

Al-Hmouz, H., Abu Hamour, B. (2017). International Do Executive Functions Differentiate Gifted Children, Children at Risk of LDs, and Average Children? Journal of Special Education, 32(1), 88-144.

Apsvalka, D., Cross, E. S., Ramsey, R. (2019). Fluid Intelligence and working memory support dissociable aspects of learning by physical but not observational practice. Journal of Cognition, 190, 170-183. https://doi.org/10.1016/i.cognition.2019.04.015

Ardila, A., Pineda, D., \& Rosselli , M. (2000). Correlation Between Intelligence Test Scores and Executive Function Measures. Journal Archives of Clinical Neuropsychology, 15(1), 31-60. https://doi.org/10.1093/arclin/15.1.31

Ardila, A. (2018). Is Intelligence Equivalent to Executive Functions? Psicothema, 30(2), 159-164. https://doi.org/10.7344/psicothema2017.329

Aubry, A., Beatrice, B., Gonthier, C. (2018). Explaining the high working memory capacity of gifted children : contribution of processing skills and executive control. Acta Psychologica, 28. https://doi.org/10.1016/i.actpsy.2021.103358

Bardo, M. T., Fishbein, D. H., \& Milich, R. (2011). Inhibitory Control and Drug Abuse Prevention: From Research to Translation. New York : Springer. https://doi.org/10.1007/978-1-4419$\underline{1268-8}$

Baron, R. A., Byrne, D. (2003). Psikologi sosial. Jakarta : Indonesia.

Benedek, M., Jauk, E., Sommer, M., Arendasy, M., Neubauer, A. C. (2014). Intelligence, creativity, and cognitive control : The common and differential involvement of executive function in intelligence and creativity. Journal of Intelligence, 46, 73-83. http://dx.doi.org/10.1016/j.intel.2014.05.007

Bernier, A., Carlson, S. M., Deschenes, M., Matte-Gagne, C. (2011). Social factors in the development of early executive functioning : a closer look at the caregiving environment. Journal of Developmental Science, 15(1), 12-24. https://doi.org/10.1111/j.14677687.2011.01093.x

Blair, C., Razza, R. P. (2007). Relating Effortful Control, Executive Function, and False Belief Understanding to Emerging Math and Literacy Ability in Kindergarten. Journal of Child Development, 78(2), 647-663. https://doi.org/10.1111/j.1467-8624.2007.01019.x

Briggs, C. J., Reis, S. M., \& Sullivan, E. E. (2008). A national view of promising programs and practices of culturally, linguistically, and ethnically diverse gifted and talented students. The Gifted Child Quarterly, 52(2), 131-145. https://doi.org/10.1177/0016986208316037

Carlson, S.M., Zelazo,P,D., \& Faja, S (2013). Executive Function. The Oxford Handbook of Developmental Psychology (Vol. 1): Body and Mind. https://doi.org/10.1093/oxfordhb/9780199958450.001.0001 
Chichekian, T., Shore, B. M. (2017). Hold Firm : Gifted Learners Value Standing One's Ground in Disagreements With a Friend. Journal for the Education of the Gifted, 40(2), 152-167. https://doi.org/10.1177/0162353217701020

Davis, A. S., Pierson, E. E., Finch, W. H. (2011). A Canonical Correlation Analysis of Intelligence and Executive Functioning. Journal of Applied Neuropsychology, 18, 61-68. https://doi.org/10.1080/09084282.2010.523392

Dehn, M. J. (2011). Working Memory and Academic Learning: Assessment and Intervention. New Jersey: John Wiley \& Sons, Inc.

Diamond, A. (2013). Executive Functions. Annual Review of Psychology, Vol. 64, 135-168. https://doi.org/10.1146/annurev-psych-113011-143750

Dombrowski, S. C., Mrazik, M. (2010). The Neurobiological Foundation of Giftedness. Roeper Review : A Journal on Gifted Education, 32(4), 224-234. https://doi.org/10.1080.02783193.2010.508154

Fay-Stammbach, T., Hawes, D. J., Meredith, P. (2014). Parenting Influences on Executive Function in Early Childhood : A Review. Journal of Society for Research in Child Development, 8(4), 258-264. https://doi.org/10.1111/cdep.12095

Ferreira, L. D., Zanini, D. S., \& Seabra, A. G. (2015). Executive function : Influence of Sex, Age, and Its Relationship with Intelligence, 25(62), 383-391. https://doi.org/10.1590/1982$\underline{43272562201512}$

Friedman, N. P., Miyake , A., Corley , R. P., Young , S. E., DeFries , J. C., \& Hewitt, J. K. (2006). Not All Executive Function Are Related to Intelligence. Psychological Science, 17, 172-179. https://doi.org/10.1111/j.1467-9280.2006.01681.x

Fugate, C. M., Gentry, M., Zentall, S. S. (2013). Creativity and Working Memory in Gifted Students With and Without Characteristic of Attention Deficit Hyperactive Disorder: Lifting the Mask. Gifted Child Quarterly, 57, 234. https://doi.org/10.1177/0016986213500069

Geake, J. G., Dodson, C. S. (2005). A neuro-psychological model of the creative intelligence of gifted $\begin{array}{llll}\text { children. } \quad \text { Gifted and } & \text { Talented }\end{array}$ https://doi.org/10.1080/15332276.2005.11673052

Giofrè, D., Mammarella, I. C., \& Cornoldi, C. (2013). The structure of working memory and how it relates to intelligence in children. Journal of Intelligence, 41(5), 396-406. https://10.1016/i.intell.2013.06.006

Godoy , S., Dias , N. M., \& Seabra, A. G. (2014). Executive and Non-Executive Gognitive Abilities in Teenagers : Differences as a Function of Intelligence. Journal of Scientific Research, 5(18). https://10.4236/psych.2014.518205

Goldstein, S., \& Naglieri, J. A. (2014). Handbook of Executive Functioning. New York: Springer. https://doi.org/10.1007/978-1-4614-8106-5 1

Guignard, J. H., Jacquet, A. Y., Lubart, T. I. (2012). Perfeksionism and Anxiety : A Paradox in Intellectual Giftedness? Journal of PLoS ONE 7(7):e41043. https://doi.org/10.1371/journal.pone.0041043 
Hornung, C., Brunner, M., Reuter, R. A. P., \& Martin, R. (2011). Children's working memory: It's structure and relationship to fluid intelligence. Journal of Intelligence, 39(4), 210-221. https://doi.org/10.1016/j.intel.2011.03.002

Huizinga, M., Dolan, C. V., \& Van der Molen, M. W. (2006). Age-related change in executive function: Developmental trends and a latent variable analysis. Neuropsychologia, 44(11), 2017-2036. https://doi.org/10.1016/j.neuropsychologia.2006.01.010

Kerr, Barbara. (2009). Encyclopedia of Giftedness, Creativity, and Talent. USA : Sage Publication, Inc. https://dx.doi.org/10.4135/9781412971959

Kent, P. (2017). Fluid Intelligence : A brief History. Journal of Applied Neuropsychology : Child, 6(3), 193-203. https://doi.org/10.1080/21622965.2017.1371480

Kyllonen, P., Kell, H. (2017). What is fluid intelligence? Can it be improved? In M. Rosen, K. Yang Hansen, \& U. Wolff (Eds.). Cognitive abilities and educational outcomes : A festschrift in honour of Jan-Eric Gustafsson. Springer International Publishing. https://doi.org/10.1007/978-3-319-43473-5 2

Leikin, M., Paz-Baruch, N., \& Leikin, R. (2013). Memory abilities in generally gifted and excellingin-mathematics adolescents. Intelligence, 41(5), 566-578. https://doi.org/10.1016/j.intell.2013.07.018

Lickliter, R. (2012). Exploring the Dynamics of Development and Evolution : Comment on Blair and Raver 2012. Journal of Developmental Psychology, 48(3), 658-661. https://doi.org/10.1037/a0027495

Maclntyre, Christine. (2008). Gifted and Talented Children 4-11 : Understanding and supporting their development. New York : Routledge.

Mahone, E. M., Hagelthorn, K. M., Cutting, L. E., Schuerholz, L. J., Pelletier, S. F., Rawlins, C., Singer, H. S., Denckla, M. B. (2002). Effect of IQ on Executive Functions Measure in Children with ADHD. Child Neuropsychology. A Journal Normal and Abnormal Development in Childhood and Adolescece, 8(1), 52-65. https://doi.org/10.1076/chin.8.1.52.8719

McCloskey, G., Perkins, L. A., \& Van Divner, B. (2009). Assessment and intervention for executive function difficulties. School-based practice in action series. New York: Routledge.

Miller, D.C (2007). Essentials of School Neuropsychological Assessment. New Jersey : John Wiley and Sons,Inc.

Miyake, A., Friedman, N. P., Emerson, M. J., Witzki, A. H., Howerter, A., \& Wager, T. D. (2000). The Unity and diversity of executive functions and their contributions to complex "frontal lobe" task : A latent variable analysis. Journal of Cognitive Psychology, 41(1), 49-100. https://doi.org/10.1006/cogp.1999.0734

Papalia , D. E., Feldman, R. D., \& Martorell, G. (2014). Menyelami Perkembangan Manusia Experience Human Development. Jakarta: Salemba Humanika.

Pfeiffer, S. I. (2018). Handbook of Giftedness in Children : Psychoeducational Theory, Research, and Best Practices Second Edition. New York : Springer. 
Renzulli, J. S. (2005). The Three Ring Conception of Giftedness: A Developmental Model For Promoting Creative Productivity Second Edition. United States: Cambridge University Press. https://doi.org/10.1017/CB09780511610455.015

Rhoades, B. L., Greenberg, M. T., Lanza, S. T., Blair, C. (2011). Demographic and familial predictors of early executive function development : Contribution of a person-centered perspective. Journal of Experimental Child Psychology, 108(3), 638-662. https://doi.org/10.1016/i.jecp.2010.08.004.

Saenz, L. V., Riba, S. S., Martinez, M. L. U., Botella, J. (2020). Measurement of Executive Functioning and High Intellectual Ability in Childhood : A Comparative Meta-Analysis. Journal of Sustainability, 12(11). https://doi.org/10.3390/su12114796

Silverman, L. K. (2013). Giftedness 101 : The Psych 101 Series. New York : Springer.

Sousa, D. A. (2009). How the Gifted Brain Learns. California : Corwin Press, Inc.

Sugiyono. (2017). Statistika untuk penelitian. Bandung : Penerbit Alfabeta.

Toll, S. W. M., Van der Ven, S. H. G., Kroesbergen, E. H., Van Luit, J. E. H. (2011). Executive Functions as Predictors of Math Learning Disabilities. Journal of Learning Disabilities, 44(6), 521-532. https://doi.org/10.1177/0022219410387302

Van Viersen, S., Kroesbergen, E. H., Slot, E. M., \& de Bree, E. H. (2014). High Reading Skills Mask Dyslexia in Gifted Children. Journal of Learning Disabilities, 49(2), 189-199. https://doi.org/10.1177/0022219414538517

Wade, C., \& Carol, T. (2007). Psikologi (Vol. 9). Jakarta: Erlangga.

Wandelken, C., Bunge, S. A., Carter, C. S. (2008). Maintaining structured information : an investigation into functions of parietal and lateral prefrontal cortices. Neuropsychologia, 46(2), 665-780. https://doi.org/10.1016/j.neuropsychologia.2007.09.015

Yazid, A. F., Zainun, A. B., Khan , A. R., \& Nik Saleh , N. S. (2018). Parenting Style among Muslim Gifted and Talented. Developing Executive Function Skills in Gifted and Talented: Using the Buletin Abqari Talk Show as a Medium, 32.

Yurgelun, D \& Todd. (2007). Emotional and cognitive change during adolescence. Current opinion in Neurobiology, 17(2), 251-257. https://doi.org/i.conb.2007.03.009 